\title{
Identification of Small Grains Genotypes Resistant to Wheat spindle streak mosaic virus
}

L. Cadle-Davidson, Department of Plant Pathology, M. E. Sorrells, Department of Plant Breeding and Genetics, S. M. Gray, United States Department of Agriculture-Agricultural Research Service (USDA-ARS), Plant Protection Research Unit, and G. C. Bergstrom, Department of Plant Pathology, Cornell University, Ithaca, NY 14853

\begin{abstract}
Cadle-Davidson, L., Sorrells, M. E., Gray, S. M., and Bergstrom, G. C. 2006. Identification of small grains genotypes resistant to Wheat spindle streak mosaic virus. Plant Dis. 90:1045-1050.

Once Wheat spindle streak mosaic virus (WSSMV) becomes established in a field, the only available control strategy is the planting of resistant genotypes. In this study, we assessed 112 genotypes of winter wheat, rye, triticale, and barley for resistance to WSSMV in a 3-year trial in a field that had been used continuously for WSSMV evaluation for over 20 years. Because resistance to WSSMV reduces the percentage of plants that develop detectable virus titer and symptoms, we collected and analyzed disease incidence data. None of the genotypes was immune to infection. Sixty-two of the regionally adapted genotypes repeatedly expressed resistance to WSSMV, thus providing growers with a choice of cultivars resistant to WSSMV. Because of a significant interaction between genotypes and environment (year), genotypes should be assessed for incidence of symptomatic plants in multiple years, particularly when differentiating intermediate responses from highly susceptible and highly resistant responses.
\end{abstract}

Additional keywords: Bymovirus, disease gradient, logistic regression, Polymyxa graminis

Wheat spindle streak mosaic virus (WSSMV), a Bymovirus in the family Potyviridae, causes significant disease resulting in measurable yield loss in winter wheat in the northeastern United States $(16,17,20)$. WSSMV putatively is vectored by the protozoan plasmodiophorid $\mathrm{Po}$ lymyxa graminis, an obligate parasite of wheat roots that can survive in dry soil without a host for at least 10 years while retaining transmissibility of the viruses it may harbor (1). Transmission occurs shortly after autumn planting (5); however, because of slow systemic viral movement (19), symptoms typically are not expressed until the following spring. In New York, symptom expression begins in early May (stem elongation stages), with typical symptoms appearing as elongated spindleshaped chlorotic streaks, each surrounding a dark green island. Symptoms fail to develop on emerging leaves when the average temperature exceeds $15^{\circ} \mathrm{C}$, but can reinitiate on growth as late as the flag leaf

Corresponding author: G. C. Bergstrom

E-mail: gcb3@cornell.edu

Current address for L. Cadle-Davidson: USDAARS, Grape Genetics Research Unit, Cornell University, Geneva, NY 14456.

Accepted for publication 13 March 2006.

DOI: 10.1094/PD-90-1045

This article is in the public domain and not copyrightable. It may be freely reprinted with customary crediting of the source. The American Phytopathological Society, 2006. given conducive weather conditions (L. Cadle-Davidson and G. C. Bergstrom, unpublished). Chemical and cultural control tactics for managing WSSMV have not been identified. Due to the longevity of WSSMV and $P$. graminis in soil even in the absence of a host, the only practical control tactic once WSSMV becomes established in a field is the planting of resistant genotypes.

Resistance to WSSMV is highly heritable and controlled by a few dominant genes $(11,12)$. In a population of recombinant inbred lines derived from a cross between resistant 'Geneva' and susceptible 'Augusta,' one major gene for resistance to WSSMV resided on chromosome arm 2DL (11). Cultivar resistance against the putative vector has not been identified $(2,3,22)$. Presumably, the vector is able to transmit WSSMV to the cortical root tissue of all host genotypes.

Resistance to WSSMV has been characterized as a reduction in the incidence of symptomatic plants but does not necessarily correspond with a reduction in virus titer or symptom severity in infected plants (7). Yield loss has been correlated to the incidence of systemically infected plants (17). In the susceptible cvs. Augusta and Frankenmuth, yield declined as much $32 \%$ associated with an increase in wheat spindle streak mosaic (WSSM) disease incidence from 0 to $100 \%$ (17). In the breeding line NY6432-10, symptoms were difficult to diagnose, and neither symptom incidence nor viral titer (detected by enzyme-linked immunosorbent assay [ELISA]) had statis- tically significant correlation with yield loss (17).

Using serological methods, WSSMV has been detected in roots of the resistant wheat cv. Geneva not expressing foliar symptoms, suggesting that resistance blocks neither transmission nor cell-to-cell movement in roots (L. Cadle-Davidson, unpublished data). In a study looking at the incidence of WSSM on individual stems in the field, a small proportion of individual Geneva plants became systemically infected with WSSMV and produced foliar symptoms (7). Highly resistant 'KS92WGRC22' had a low incidence of symptoms on individual plants and, on those plants that were symptomatic, individual stems were asymptomatic (7). Together, these observations suggest that one mechanism of resistance to WSSMV is to restrict the movement of virus into foliar portions of the plant and that this restriction can be overcome in individual plants or stems, resulting in foliar symptoms.

When evaluating resistance, researchers commonly either use a subjective wholeplot severity (or yellowing) scale $(11,18)$ or gather incidence data and convert that to relative ranks or a "severity scale" $(9,11)$. These methods have the advantage of being easily analyzed and are amenable to multiple comparisons analyses, such as Duncan's (versus a check variety) or Fisher's least significant difference. Another valid statistical method is the use of half-normal probability plots, which can be used for analysis of unreplicated trials (14). The downfall of half-normal probability plot analysis is the subjectivity required in the analysis itself (13). Logistic regression also has been employed to analyze incidence data and detect quantitative variation in a trait while maintaining the ability to demarcate discrete relative ratings based on the interpreter's needs (4).

Our aim in this study was to evaluate resistance to WSSMV in regionally adapted cultivars and advanced breeding lines.

\section{MATERIALS AND METHODS}

Plant materials. The genotypes included in this study composed two sets of genotypes selected for evaluation by the small grains breeding program at Cornell University, Ithaca, NY. One set included only soft white winter wheat (SWWW) genotypes, the majority being advanced breeding lines. The other set was predomi- 
Table 1. Average percentage of Wheat spindle streak mosaic virus-symptomatic stems for each year for genotypes with 3 years' data (check genotypes)

\begin{tabular}{|c|c|c|c|c|}
\hline \multirow[b]{2}{*}{ Check } & \multirow[b]{2}{*}{ Genotype $^{b}$} & \multicolumn{3}{|c|}{ Year $^{\mathrm{a}}$} \\
\hline & & $2000(\%)$ & $2002(\%)$ & $2003(\%)$ \\
\hline 1 & TW97613 & 62.3 & 65.7 & 94.3 \\
\hline 2 & Roane & 74.3 & 46.7 & 90.0 \\
\hline 3 & Pioneer 2548 & nd & 41.1 & 76.1 \\
\hline 4 & Superior & 16.7 & 64.3 & 91.0 \\
\hline 5 & A94-1315 & 48.3 & 29.0 & 78.3 \\
\hline 6 & Sawyer & 49.0 & 27.7 & 51.0 \\
\hline 7 & Foster & 57.7 & 36.7 & 23.3 \\
\hline 8 & OH 530 & 29.0 & 35.7 & 37.7 \\
\hline 9 & IL 91-15911 & 51.0 & 19.0 & 31.0 \\
\hline 10 & Sisson & 32.3 & 25.7 & 27.7 \\
\hline 11 & Marilee & 8.9 & 46.7 & nd \\
\hline 12 & Freedom & 27.7 & 17.7 & 33.3 \\
\hline 13 & AC Ron & 11.0 & 26.7 & 20.0 \\
\hline 14 & Va 96W-247 & 32.3 & 6.7 & 12.3 \\
\hline 15 & NYBatavia (MS) & 21.0 & 4.3 & 23.3 \\
\hline 16 & Cardinal & nd & 2.3 & 28.9 \\
\hline 17 & Watford & 5.7 & 0.0 & 14.3 \\
\hline 18 & Whitby & 1.0 & 4.3 & 14.3 \\
\hline 19 & Harus (MR) & 4.0 & 3.3 & 11.7 \\
\hline 20 & Pioneer $25 \mathrm{~W} 33$ & 2.3 & 9.0 & 7.7 \\
\hline 21 & Patton & 7.7 & 1.0 & 10.0 \\
\hline 22 & Houser & 11.0 & 1.0 & 5.7 \\
\hline 23 & Pearl & 0.0 & 1.0 & 13.3 \\
\hline 24 & Caledonia & 1.0 & 1.0 & 10.0 \\
\hline 25 & Pioneer 2510 & 10.0 & 1.0 & 0.0 \\
\hline 26 & Trical $815(\mathrm{Tcl})$ & 7.7 & 2.3 & 1.0 \\
\hline 27 & Mendon & 5.7 & 1.0 & 3.3 \\
\hline 28 & Geneva $(\mathbf{R})$ & 2.3 & 3.3 & 4.0 \\
\hline 29 & KY86C-61-8 & 1.0 & 2.3 & 5.7 \\
\hline 30 & Bavaria & 0.0 & 1.0 & 6.7 \\
\hline 31 & Hoffman 37 & 1.0 & 2.3 & 4.3 \\
\hline 32 & Richland & nd & 0.0 & 5.0 \\
\hline 33 & Presto $(\mathrm{Tcl})$ & 3.3 & 3.3 & 0.0 \\
\hline 34 & Cayuga & 1.7 & 1.0 & 1.7 \\
\hline 35 & Pioneer 2540 & 0.0 & 3.3 & 1.0 \\
\hline 36 & RSIBG 1998 (Tcl) & 0.0 & 2.3 & 0.0 \\
\hline 37 & Aroostock (rye) & nd & 1.1 & 0.0 \\
\hline 38 & Pioneer 25R37 & nd & 1.1 & 0.0 \\
\hline 39 & RSI AZ 1998 (Tcl) & nd & 0.0 & 0.0 \\
\hline
\end{tabular}

a Spring in which symptoms were assessed; average incidence of infected stems for that year based on 3 or 6 replications of 30 ; nd $=$ not determined.

${ }^{\mathrm{b}}$ Genotypes included in the study for all 3 years. Wheat, unless otherwise stated; $\mathrm{Tcl}=$ triticale. Previously published resistance ratings are in bold: $\mathrm{MS}=$ moderately susceptible, $\mathrm{MR}=$ moderately resistant, and $\mathrm{R}=$ resistant.

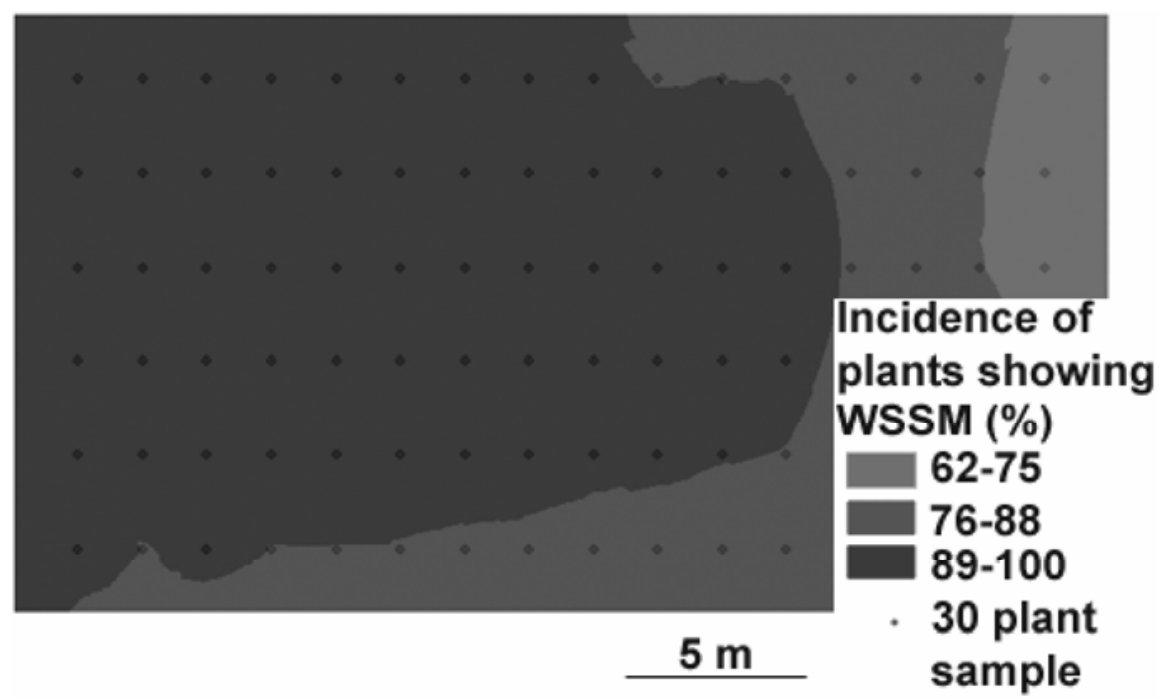

Fig. 1. Wheat spindle streak mosaic (WSSM) disease distribution for 'NY88036-8082' in 2003. Point locations represent the middle of each row of the susceptible check NY88036-8082 wheat, which was planted in every sixth row throughout the nursery. Location and corresponding incidence data were entered into a geographic information system and Kriging interpolation was performed. Shading represents a point estimate for the percent incidence of WSSM. The map is oriented with north at its top. nantly soft red winter wheat (SRWW) cultivars, but included several barley, rye, and triticale cultivars and some SWWW cultivars for comparison across the two sets. In 1999 to 2000, our nursery included the two sets of 40 genotypes, with several of the genotypes being present in both sets. Therefore, up to 18 rows (three replicates, two sets, 3 years) of a single genotype could have been assessed, as was the case for 'Harus' and 'Cayuga.' In subsequent years, as some of the original genotypes were replaced in the breeding program, we chose to retain genotypes to obtain multiple years of data. By the end of the study, we had evaluated 112 different genotypes, 32 of which were evaluated in all 3 years (Table 1).

Field evaluation. The SWWW and SRWW genotypes were planted at Caldwell Field (Williamson very fine sandy loam soil; Ithaca, NY) as two separate experiments in a randomized complete block design with three replications of single, 1-m rows with seed planted at 5 $\mathrm{g} / \mathrm{m}$. The WSSMV nursery in Caldwell Field has been planted to winter wheat continuously since the 1980s, and WSSM symptoms have been uniform throughout the nursery in most years.

Each year the WSSMV nursery was plowed, disked, and harrowed, incorporating 10-20-20 NPK at $225 \mathrm{~kg} \mathrm{ha}^{-1}$ prior to September planting. Plants were top dressed with ammonium nitrate at $84 \mathrm{~kg}$ $\mathrm{ha}^{-1}$ in early April. In early May, during peak symptom expression, the majority of stems was harvested from each row. A subsample was constructed by arbitrarily plucking 30 stems from the pile of harvested stems. Each of the 30 stems was examined in a laboratory setting and rated individually for presence or absence of typical symptoms of WSSM (i.e., elongated chlorotic lesions tapered at each end and with a green island in the center). These highly definitive symptoms were considered diagnostic of WSSM based on positive confirmation of coat protein of WSSMV in symptomatic plants from this nursery when assayed by double-antibody sandwich (DAS)-ELISA over more than a decade of testing (6-8; G. C. Bergstrom and S. M. Gray, unpublished). During that same historical period, Soilborne wheat mosaic virus was not detected in this nursery by visual inspection or serological tests (G. C. Bergstrom and S. M. Gray, unpublished), nor was it detected visually during the period of this study. In the first year of this study, 2000, symptomatic leaves of the check cvs. Pioneer 2548, Mendon, and Geneva tested positive for WSSMV by DAS-ELISA. No serology was performed in subsequent years of this study. In 2001, no viral symptoms developed in the field, and ratings were not taken.

Some of the cultivars in the study had been rated for WSSMV resistance in previous publications and are thus denoted in 
Tables 1 and 2 for reference. In studies conducted in New York, cvs. Geneva, Harus, and NYBatavia have been suggested to be resistant, moderately resistant, and moderately susceptible, respectively (11,15-17,21).

Characterizing disease distribution. To detect and potentially account for nonuniform distribution of WSSMV at Caldwell Field, the susceptible check 'NY88036-8082' was planted in every sixth row for the 2002-03 growing season. Incidence was assessed as described above, and the results were entered into a geographic information system (ArcGIS; ESRI, Redlands, CA) along with the corresponding location data for each row. For the purpose of interpolation, each row was defined by the midpoint of the row, and Kriging analysis was performed (10). The resulting surface was intended to be diagnostic and to suggest whether our statistical analysis ought to take disease distribution into account (Fig. 1).

Statistical analysis. Proc Logistic in SAS (SAS Institute Inc., Cary, NC) was used to calculate a $95 \%$ Wald confidence interval for the odds ratio, setting the incidence of each genotype against a check genotype selected when programming. Three scenarios exist for this confidence interval: (i) if the interval contained 1, WSSM incidence was not significantly different than the check genotype; (ii) if the interval contained only numbers less than 1 , the genotype had significantly less WSSM incidence than the check; or (iii) if the interval contained only numbers greater than 1, the genotype had significantly greater WSSM incidence than the check (all scenarios at $\alpha=0.05$ ).

The analysis was repeated so that each of 39 cultivars evaluated in two or three seasons (Table 1) was the check genotype for one iteration. By encoding a 0 for scenario (i), a -1 for scenario (ii), and a 1 for scenario (iii), the statistical analysis gives rise to a matrix comparing the set of all genotypes with the set of check genotypes (Fig. 2). Summing across comparisons with all check genotypes yields a statistic for relative WSSM incidence or, loosely, susceptibility. Sorting this matrix from resistant (most negative number) to susceptible (largest positive number) for both the set of all genotypes and the set of check genotypes allows for graphic representation of relative resistance. Using this method, a model was analyzed with only genotype and year as predictors because the spatial variability of disease incidence in the WSSMV nursery was negligible.

\section{RESULTS}

Disease incidence and distribution. Disease incidence was high in spring 2000 (20.3\% average incidence across all genotypes; $61.6 \%$ average for TW97613, Roane, and A94-1315, the three genotypes
Table 2. Summary of the average percentage of Wheat spindle streak mosaic virus-symptomatic stems for all genotypes across all years

\begin{tabular}{|c|c|c|c|c|}
\hline Genotype $^{a}$ & Average $(\%)^{b}$ & $\operatorname{Minimum}(\%)^{\mathrm{c}}$ & $\operatorname{Maximum}(\%)^{\mathrm{d}}$ & Sampled rows ${ }^{\mathrm{e}}$ \\
\hline TW060-075 & 90.0 & 86.7 & 93.3 & 3 \\
\hline VAN98W-170WS & 85.6 & 73.3 & 96.7 & 3 \\
\hline NY88036-8082 & 83.2 & 60.0 & 100.0 & 15 \\
\hline Century II & 76.7 & 63.3 & 90.0 & 3 \\
\hline TW97613 & 74.1 & 46.7 & 96.7 & 9 \\
\hline NY89073SP-8110 & 72.2 & 40.0 & 96.7 & 6 \\
\hline Roane & 70.4 & 33.3 & 96.7 & 9 \\
\hline TW97611 & 70.0 & 53.3 & 83.3 & 3 \\
\hline Pioneer 25R18 & 67.8 & 60.0 & 83.3 & 3 \\
\hline Pioneer 2548 & 64.4 & 40.0 & 100.0 & 9 \\
\hline CaledoniaResel-T & 57.8 & 40.0 & 80.0 & 3 \\
\hline Superior & 56.2 & 10.0 & 96.7 & 9 \\
\hline Va97W-375WS & 48.9 & 40.0 & 63.3 & 3 \\
\hline NY89073SP-8145 & 47.8 & 0.0 & 93.3 & 6 \\
\hline NY89056SP-9060 & 47.8 & 36.7 & 60.0 & 3 \\
\hline A94-1315 & 45.0 & 13.3 & 83.3 & 8 \\
\hline Sawyer & 42.6 & 6.7 & 66.7 & 9 \\
\hline Genesis 9953 & 42.2 & 0.0 & 76.7 & 6 \\
\hline NY88048-8185 & 40.0 & 16.7 & 70.0 & 9 \\
\hline Foster & 39.3 & 13.3 & 80.0 & 9 \\
\hline NY89088-9101 & 36.7 & 26.7 & 50.0 & 3 \\
\hline NY89059SP-8094 & 36.1 & 13.3 & 80.0 & 6 \\
\hline OH 530 & 34.1 & 10.0 & 66.7 & 9 \\
\hline IL 91-15911 & 33.7 & 6.7 & 76.7 & 9 \\
\hline M98*2152 & 33.3 & 23.3 & 40.0 & 3 \\
\hline CaledoniaResel-SS & 31.1 & 13.3 & 50.0 & 3 \\
\hline $\mathrm{T} 123$ & 30.0 & 13.3 & 46.7 & 6 \\
\hline Sisson & 28.5 & 20.0 & 40.0 & 9 \\
\hline Pioneer 25R78 & 26.7 & 23.3 & 30.0 & 3 \\
\hline Freedom & 26.3 & 6.7 & 53.3 & 9 \\
\hline TW96202 & 25.8 & 13.3 & 43.3 & 6 \\
\hline AC Ron & 19.3 & 3.3 & 50.0 & 9 \\
\hline NY89088-8152 & 18.9 & 0.0 & 46.7 & 6 \\
\hline NY89088-9118 & 17.8 & 13.3 & 23.3 & 3 \\
\hline NY88045-8164 & 17.8 & 10.0 & 26.7 & 3 \\
\hline Va 96W-247 & 17.0 & 0.0 & 53.3 & 9 \\
\hline VA97W-375 & 16.7 & 3.3 & 30.0 & 6 \\
\hline NYBatavia (MS) & 16.3 & 0.0 & 33.3 & 9 \\
\hline NY89078SP-8184 & 16.1 & 3.3 & 33.3 & 6 \\
\hline Cardinal & 15.6 & 0.0 & 43.3 & 6 \\
\hline NY89082-7159 & 15.0 & 0.0 & 43.3 & 6 \\
\hline NY89065SP-8113 & 13.7 & 0.0 & 43.3 & 9 \\
\hline Marilee & 12.2 & 6.7 & 23.3 & 6 \\
\hline VA98W-593 & 10.6 & 0.0 & 23.3 & 6 \\
\hline NY89063-9126 & 10.0 & 10.0 & 10.0 & 3 \\
\hline NY88046-8138 & 10.0 & 3.3 & 20.0 & 5 \\
\hline NY89035SP-8162 & 7.9 & 0.0 & 17.5 & 6 \\
\hline NY89088-8173 & 7.8 & 0.0 & 16.7 & 9 \\
\hline NY89088-7401 & 7.8 & 0.0 & 13.3 & 6 \\
\hline NY91017-8080 & 7.2 & 0.0 & 13.3 & 6 \\
\hline NY89081-7161 & 6.8 & 0.0 & 26.7 & 6 \\
\hline Whitby & 6.7 & 0.0 & 20.0 & 9 \\
\hline Watford & 6.7 & 0.0 & 23.3 & 9 \\
\hline NY89064SP-7139 & 6.7 & 0.0 & 26.7 & 6 \\
\hline Harus (MR) & 6.3 & 0.0 & 23.3 & 18 \\
\hline Pioneer 25W33 & 6.3 & 0.0 & 20.0 & 9 \\
\hline Patton & 6.3 & 0.0 & 20.0 & 9 \\
\hline Houser & 5.9 & 0.0 & 20.0 & 9 \\
\hline NY89086SP-9203 & 5.6 & 0.0 & 13.3 & 6 \\
\hline NY89037SP-8140 & 5.6 & 0.0 & 20.0 & 6 \\
\hline CaledoniaResel-VT & 5.6 & 3.3 & 6.7 & 3 \\
\hline NY89086-7120 & 5.0 & 0.0 & 16.7 & 6 \\
\hline NY89052-9140 & 5.0 & 0.0 & 13.3 & 6 \\
\hline \multirow[t]{2}{*}{ Pearl } & 4.8 & 0.0 & 26.7 & 9 \\
\hline & & & \multicolumn{2}{|c|}{ (continued on next page) } \\
\hline
\end{tabular}

${ }^{\mathrm{a}}$ Wheat, unless otherwise stated. Previously published resistance ratings are in bold: MS = moderately susceptible, $\mathrm{MR}=$ moderately resistant, and $\mathrm{R}=$ resistant.

${ }^{\mathrm{b}}$ Average percent incidence: the sum of symptomatic stems in all replications in all years tested divided by the total number of stems assessed. Overall $=$ overall incidence percentage.

${ }^{c}$ Minimum percent of symptomatic stems in any replication in any year.

${ }^{\mathrm{d}}$ Maximum percent of symptomatic stems in any replication in any year.

${ }^{\mathrm{e}}$ Total number of replications tested, which may be the result of 1 to 3 years as an entry in the trial in one or both of the genotype sets. 
Table 2. (continued from preceding page)

\begin{tabular}{|c|c|c|c|c|}
\hline Genotype $^{a}$ & Average $(\%)^{b}$ & Minimum (\%) & Maximum (\%) & Sampled rows ${ }^{\mathrm{e}}$ \\
\hline NY89014SP-9220 & 4.7 & 0.0 & 10.0 & 5 \\
\hline TW044-065 & 4.4 & 0.0 & 10.0 & 3 \\
\hline NY89066-7131 & 4.4 & 0.0 & 13.3 & 6 \\
\hline NY89052-7142 & 4.4 & 0.0 & 10.0 & 6 \\
\hline NY87048W-7388 & 4.4 & 0.0 & 16.7 & 6 \\
\hline D8006 & 4.4 & 3.3 & 6.7 & 3 \\
\hline CaledoniaResel-A & 4.4 & 0.0 & 6.7 & 3 \\
\hline Trical 815 (triticale) & 3.3 & 0.0 & 23.3 & 12 \\
\hline Mendon & 3.3 & 0.0 & 10.0 & 9 \\
\hline McCormick & 3.3 & 0.0 & 10.0 & 6 \\
\hline NY92145BW-9144W & 3.3 & 0.0 & 10.0 & 3 \\
\hline NY91028-9073 & 3.3 & 0.0 & 6.7 & 3 \\
\hline NY89052SP-9232 & 3.3 & 0.0 & 6.7 & 6 \\
\hline NY88072-9070W & 3.3 & 0.0 & 6.7 & 3 \\
\hline Geneva (R) & 3.1 & 0.0 & 13.3 & 17 \\
\hline KY86C-61-8 & 3.0 & 0.0 & 16.7 & 9 \\
\hline Trical 336 (triticale) & 2.8 & 0.0 & 6.7 & 6 \\
\hline Hoffman 37 & 2.6 & 0.0 & 6.7 & 9 \\
\hline Bavaria & 2.6 & 0.0 & 13.3 & 9 \\
\hline Richland & 2.5 & 0.0 & 13.3 & 12 \\
\hline Presto (Triticale) & 2.2 & 0.0 & 6.7 & 9 \\
\hline NY91028SP-9245W & 2.2 & 0.0 & 3.3 & 3 \\
\hline NY88046SP-9230W & 2.2 & 0.0 & 3.3 & 3 \\
\hline NY89056SP-7208 & 2.0 & 0.0 & 6.7 & 5 \\
\hline NY90008-8092 & 1.7 & 0.0 & 3.3 & 6 \\
\hline Pioneer 2540 & 1.5 & 0.0 & 6.7 & 9 \\
\hline Cayuga & 1.5 & 0.0 & 3.3 & 18 \\
\hline NY93251R-9141W & 1.1 & 0.0 & 3.3 & 3 \\
\hline NY88041-9063W & 1.1 & 0.0 & 3.3 & 3 \\
\hline Elmira (barley) & 1.1 & 0.0 & 6.7 & 6 \\
\hline CaledoniaResel-L & 1.1 & 0.0 & 3.3 & 3 \\
\hline Caledonia & 1.1 & 0.0 & 3.3 & 15 \\
\hline Pioneer 25R37 & 0.8 & 0.0 & 3.3 & 12 \\
\hline RSIBG 1998 & 0.7 & 0.0 & 3.3 & 9 \\
\hline Pioneer 2510 & 0.7 & 0.0 & 3.3 & 9 \\
\hline TW005-008 & 0.6 & 0.0 & 3.3 & 6 \\
\hline RSI111 & 0.6 & 0.0 & 3.3 & 6 \\
\hline McGregor (barley) & 0.6 & 0.0 & 3.3 & 6 \\
\hline CaledoniaResel-S & 0.6 & 0.0 & 3.3 & 6 \\
\hline Aroostock (rye) & 0.6 & 0.0 & 3.3 & 6 \\
\hline U-1273-5-18-8 & 0.0 & 0.0 & 0.0 & 6 \\
\hline TW006-007 & 0.0 & 0.0 & 0.0 & 6 \\
\hline RSI AZ 1998 (triticale) & 0.0 & 0.0 & 0.0 & 6 \\
\hline Red Caledonia & 0.0 & 0.0 & 0.0 & 3 \\
\hline Pioneer 25R23 & 0.0 & 0.0 & 0.0 & 3 \\
\hline NY89025-9111W & 0.0 & 0.0 & 0.0 & 3 \\
\hline McDermott & 0.0 & 0.0 & 0.0 & 5 \\
\hline Bobcat (triticale) & 0.0 & 0.0 & 0.0 & 3 \\
\hline Overall & 17.1 & 0.0 & 100.0 & 738 \\
\hline
\end{tabular}

rated most susceptible across all three years; Table 1) and 2003 (20.6\% for all genotypes; $87.5 \%$ for the three most susceptible genotypes) and moderate in 2002 (12.0\% for all genotypes; $47.1 \%$ for the three most susceptible genotypes), but no WSSM disease symptoms were detected in 2001. Over the three sampling years, the average incidence ranged from 0 to $90 \%$ for individual genotypes, with the average incidence of all genotypes being $17.1 \%$ (Table 2). A relatively uniform disease incidence was observed across the field, with the exception of a slight disease gradient detected near the western border of the plot in 2003 (Fig. 1). Most registered cultivars that currently are grown in the Northeast had relatively low incidence of WSSMV. The more susceptible genotypes in the study were breeding lines and cultivars not grown currently in the Northeast. intersect. Therefore, Figure 2 depicts several overlapping incidence classes and shows that 69 of the genotypes tested are significantly more susceptible than the most resistant genotype, RSI AZ 1998 (or that 43 of the genotypes are not significantly more susceptible).

In the current study, Geneva (check cultivar no. 28) did not have significantly different WSSM incidence than the 62 most resistant genotypes, including check cultivars no. 20 to 39 (Fig. 2). Harus (check cultivar no. 19) had significantly lower incidence of WSSM than check cultivars no. 1 to 16 , significantly higher incidence than check cultivars no. 27 to 39 , and not significantly different incidence than check cultivars no. 17 to 26. NYBatavia (check cultivar no. 15) had significantly lower incidence of WSSM than check cultivars no. 1 to 11 , significantly higher incidence than check cultivars no. 17 to 39 , and not significantly different incidence than check cultivars no. 12 to 16 . These results support the previous rankings of relative resistance of these three cultivars.

\section{DISCUSSION}

In New York, nearly every field with a history of small grains production is infested with WSSMV (16), and planting cultivars resistant to WSSMV is the only practical approach to managing the disease once WSSMV is introduced. Geneva, Harus, and NYBatavia previously have been suggested to be resistant, moderately resistant, and moderately susceptible, respectively $(11,15$ 17,21). Therefore, these three cultivars were included as checks in our evaluation of 112 cultivars and advanced breeding lines over 3 years of variable disease incidence. The relative incidence of WSSM in these cultivars supported their previous rankings. Sixty-two of the tested genotypes exhibited a high level of resistance to WSSMV, similar to Geneva, based on consistently low disease incidence.

Our data provide evidence that cultivars planted by New York wheat growers today are more resistant than cultivars commonly grown in the 1980s $(15,16)$. Resistant cultivars such as Caledonia and Richland account for major percentages of New York wheat acreage today and many promising breeding lines also have resistance. However, highly susceptible cultivars also are available, suggesting that vigilance still is warranted in cultivar selection by New York growers. Growers and seed distributors can use our results to select regionally adapted cultivars with resistance to WSSMV.

Resistance evaluation using mechanical inoculation of leaves with WSSMV has not corresponded with resistance evaluation in the field (7), presumably because resistance limits root-to-shoot movement and not movement within the shoots. Be- 


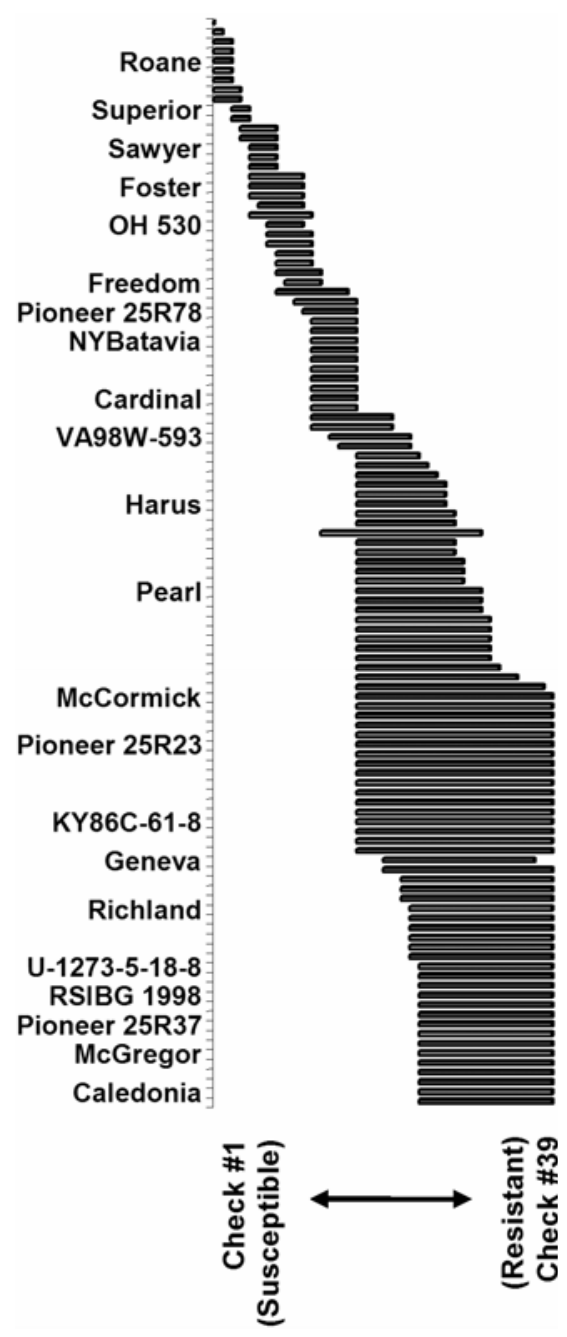

Fig. 2. Relative resistance of 112 small grains genotypes to Wheat spindle streak mosaic virus (WSSMV) based on disease incidence. Each horizontal bar is the confidence interval for disease incidence of one $y$-axis genotype relative to disease incidence of $\mathrm{x}$-axis genotypes. The $y$-axis represents the entire set of 112 genotypes assessed for resistance to WSSMV and sorted from most susceptible (top) to most resistant (bottom). For readability, only 23 genotypes of interest are labeled. The $\mathrm{x}$-axis represents 39 check genotypes (Table 1) sorted from most susceptible (left) to most resistant (right). Genotypes on the y-axis (listed in the order of Table 2) with overlapping bars did not have significantly different percent incidences of wheat spindle streak mosaic disease over the course of the study, relative to the check cultivars represented on the $\mathrm{x}$-axis.

cause protocols for efficient WSSMV inoculation of roots have not been developed (and because evaluation based on mechanical root inoculation also may not correspond with evaluations in the field), resistance still must be assessed in field trials. Although labor-intensive, evaluation of the incidence of WSSM symptoms in field trials is straightforward and the results can be applied directly to genotype selection. In some years, however, in a subset of planting dates, resistance is less effective, resulting in significant genotype-planting date interactions (5). Fur- thermore, given the environmental sensitivity of symptom expression, reliable evaluation of resistance requires compilation of multiple years of replicated data. Due to the complexity of the pathosystem and its interaction with environment, adjacent individual plants of the same genotype often respond differently to the same conducive environment. Assessing the incidence of WSSM in a population or row takes this variability into account.

Because assessment of incidence is labor intensive, most evaluations of resistance to soilborne viruses use a whole-plot severity (yellowing) scale, which is essentially an index combining percent incidence and individual plant severity. Although powdery mildew and other springtime foliar diseases can complicate visual whole-plot WSSM assessment, when conducted carefully, whole-plot assessments can adequately distinguish WSSMV-susceptible from WSSMVresistant genotypes. However, in addition to the subjectivity required in classifying relative symptom production, whole-plot assessments may not discern the quantitative variation in WSSMV resistance that we have identified here. By quantifying percent incidence, the subjectivity of the data collection was minimized. Furthermore, classification of the genotypes did not require subjectivity, and minor differences in relative resistance to WSSMV could be discerned. The ability to detect subtle quantitative variation is critical to a fundamental understanding of resistance.

Because resistance to WSSMV is expressed as a reduction in the incidence of symptomatic plants or stems, the appropriate method for evaluating resistance is to analyze incidence. Logistic analysis of our disease incidence data showed a significant interaction between genotype and year, partly due to the effect of soil microenvironment on WSSMV transmission and the age-dependent susceptibility of wheat genotypes (5). This statistical interaction can result from changes in percent incidence in different years for genotypes even if relative susceptibility of genotypes remains the same. This phenomenon is common because resistant genotypes such as Cayuga wheat have low incidence of WSSM symptoms in most years but the incidence in susceptible genotypes such as IL 91-15911 wheat may fluctuate greatly depending on environment and disease pressure. Genotypeyear interactions also can result from changes in relative susceptibility of genotypes in different years. One example of this was 'Superior' wheat which, in the first year, had moderate incidence of WSSM but, in the last 2 years, had high incidence. Therefore, our data reemphasize the need for WSSM symptoms to be assessed in multiple environments (locations, years, or both) to increase confidence that a genotype is truly resistant or to improve the resolution of classification for genetic studies.

\section{ACKNOWLEDGMENTS}

This research was supported by Cornell University Hatch Projects NYC153472, NYC153433, and NYC149419; a grant from the New York State IPM Program; a fellowship to L. Cadle-Davidson from the Storkan-Hanes-McCaslin Research Foundation; and a graduate research assistantship to L. CadleDavidson from the Department of Plant Pathology, Cornell University, Ithaca, NY. The plots were expertly aligned, planted, and managed by $\mathrm{D}$. Benscher and D. Valenta.

\section{LITERATURE CITED}

1. Adams, M. J. 1990. Epidemiology of fungallytransmitted viruses. Soil Use Manage. 6:184189.

2. Adams, M. J., Jones, P., and Swaby, A. G. 1987. The effect of cultivar used as host for Polymyxa graminis on the multiplication and transmission of Barley yellow mosaic virus (BaYMV). Ann. Appl. Biol. 110:321-327.

3. Adams, M. J., Swaby, A. G., and Macfarlane, I. 1986. The susceptibility of barley cultivars to Barley yellow mosaic virus (BaYMV) and its fungal vector, Polymyxa graminis. Ann. Appl. Biol. 109:561-572.

4. Cadle-Davidson, L. 2003. Transmission of and resistance to soilborne viruses of wheat. Ph.D. dissertation, Cornell University, Ithaca, NY.

5. Cadle-Davidson, L., and Bergstrom, G. C. 2004. The effects of post-planting environment on the incidence of soilborne viruses of small grains. Phytopathology 94:527-534.

6. Carroll, J. E., Bergstrom, G. C., and Gray, S M. 1992. Detection of coat protein of Wheat spindle streak mosaic virus is positively correlated with characteristic symptom expression. (Abstr.) Phytopathology 82:1147.

7. Carroll, J. E., Bergstrom, G. C., and Gray, S M. 2002. Assessing the resistance of winter wheat to Wheat spindle streak mosaic bymovirus. Can. J. Plant Pathol. Rev. Can. Phytopathol. 24:465-470

8. Carroll, J. E., Gray, S. M., and Bergstrom, G. C. 1995. Use of antiserum to a New York isolate of Wheat spindle streak mosaic virus to detect related Bymoviruses from North America, Europe, and Asia. Plant Dis. 79:346-353.

9. Dahlberg, J. A., Bandyopadhyay, R., Rooney, W. L., Odvody, G. N., and Madera-Torres, P. 2001. Evaluation of sorghum germplasm used in US breeding programmes for sources of sugary disease resistance. Plant Pathol. 50:681-689.

10. Goovaerts, P. 1992. Factorial Kriging analysis-a useful tool for exploring the structure of multivariate spatial soil information. J. Soil Sci. 43:597-619.

11. Khan, A. A., Bergstrom, G. C., Nelson, J. C., and Sorrells, M. E. 2000. Identification of RFLP markers for resistance to Wheat spindle streak mosaic bymovirus (WSSMV) disease. Genome 43:477-482.

12. Koevering, V. M., Haufler, K. Z., Fulbright, D. W., Isleib, T. G., and Everson, E. H. 1987 Heritability of resistance in winter wheat to Wheat spindle streak mosaic virus. Phytopathology 77:742-744

13. Lawson, J., Grimshaw, S., and Burt, J. 1998. A quantitative method for identifying active contrasts in unreplicated factorial designs based on the half-normal plot. Comput. Stat. Data Anal. 26:425-436.

14. Lenth, R. V. 1989. Quick and easy analysis of unreplicated factorials. Technometrics 31:469473.

15. Miller, N. R., Bergstrom, G. C., and Gray, S. M. 1988. Assessment of the occurrence and impact of viral diseases of winter wheat in New York State in 1988. (Abstr.) Phyto- 
pathology 78:1509.

16. Miller, N. R., Bergstrom, G. C., and Gray, S. M. 1991. Identity, prevalence, and distribution of viral diseases of winter wheat in New York in 1988 and 1989. Plant Dis. 75:1105-1109.

17. Miller, N. R., Bergstrom, G. C., and Sorrells, M. E. 1992. Effect of Wheat spindle streak mosaic virus on yield of winter wheat in New York. Phytopathology 82:852-857.

18. Mueller, D. S., Hartman, G. L., Nelson, R. L., and Pedersen, W. L. 2002. Evaluation of Glycine max germplasm for resistance to Fusarium solani $\mathrm{f}$. sp. glycines. Plant Dis. 86:741746.

19. Schenk, P., Sohn, A., Adams, M. J., Antoniw, J. F., Hamacher, J., and Steinbiss, H. H. 1995. Movement of Bymoviruses and functions of RNA2-encoded proteins of Barley yellow mosaic virus. Agronomie 15:387-391.

20. Slykhuis, J. T., and Barr, D. J. S. 1978. Con- firmation of Polymyxa graminis as a vector of Wheat spindle streak mosaic virus. Phytopathology 68:639-644.

21. Sorrells, M. E., and Bergstrom, G. C. 1998 Registration of 'NYBatavia' wheat. Crop Sci. 38:551-551.

22. Yili, R., Zou, W. H., and Chen, J. P. 1990. Quantitative assay of resting spores of $P o$ lymyxa graminis on barley roots. Ann. Appl. Biol. 117:343-347. 